\title{
EL IV CONGRESO DEL PARTIDO \\ COMUNISTA DE CUBA
}

\author{
Eva Anduiza Perea $(*)$
}

\section{INTRODUCCION.}

Entre los días 10 y 14 del mes de octubre de 1991, tuvo lugar en Santiago de Cuba el IV Congreso del Partido Comunista Cubano, sin periodistas ni invitados extranjeros, en un ambiente de expectación internacional. Abandonada por sus antiguos compañeros en el camino del comunismo, en bancarrota, asfixiada por el bloqueo norteamericano, y con las despensas vacías, Cuba atraviesa uno de los momentos más críticos de su historia. Este Congreso era esperado por muchos como el punto de inflexión que abriría el paso hacia una serie de reformas que se perciben como inevitables.

Sin embargo, en estos cuatro días se dejó bien claro que de momento no habrá cambios importantes: continuación en la linea martiana y marxista, rechazo absoluto a la economía de mercado y al pluripartidismo, y discurso nacionalista y antiimperialista. No obstante, las pocas novedades introducidas merecen ser estudadas con cierto detenimiento porque quizá de ellas puedan derivarse cambios mayores, teniendo en cuenta la situación económica límite que vive la isla.

\section{EL DESARROLLO DEL CONGRESO.}

El 18 de marzo de este año Granma publica el llamamiento al IV Congreso del Partido Comunista. El discurso se estructura siguiendo los principios clásicos de la revolución, aunque desde una perspectiva más autonomista y nacionalista, dada la situación internacional. No se esconden los problemas a los que se enfrenta el país pero tampoco se duda de que el pueblo cuabano los pueda resolver en solitario. Aunque se deja entrever cierto cuestionamiento de los métodos, los cambios se darán siempre dentro de la revolución.

Esta idea se confirma con el discurso inaugural del Primer Secretario del Partido de Santiago de Cuba, Esteban Lazo, que termina su alocución con el lema "Socialismo o muerte, Patria o muerte, ¡venceremos!”. Lo más sorprendente de esta primera jornada fue la ausencia de la mitad de los delegados de las FAR y del Ministerio del Interior, entre ellos Raúl Castro, ministro de Defensa y Abelardo Colomer, responsable de Interior. Esto, junto al carácter cerrado del Congreso ha dado lugar a múltiples especulaciones sobre la existencia de disensiones en el seno del Partido.

Las modificaciones que se van aprobando a lo largo de los días siguientes se pueden clasificar en aspectos políticos y aspectos económicos.

\section{ASPECTOS POLITICOS.}

En el ámbito de lo político los principales retos consistían en desburocratizar el aparato del Partido y modificar ciertos elementos para conseguir un sistema de representación más democrático, siempre dentro de los estrechos límites que permite la existencia de un único partido.

La eliminación de la Secretaría del Comité Central puede suponer cierta voluntad de separar las funciones del Estado y del Partido. La Secretaría, compuesta por Fidel Castro, Raúl Castro, Carlos Aldana, Jose Ramón Machado Ventura y Julián Rizo, controlaba todos los Ministerios del Gobierno Cubano y ejercía las funciones de un gobierno paralelo. Lo que aún no puede deducirse de las informaciones oficiales es si sus funciones van a ser simplemente suprimidas o bien pasarán bajo el control directo del buró político. Esto ya ocurrió el año pasado con el departamento militar del Comité Central que pasó a ser la comisión militar del polit buró.

Siguiendo el plan de reducción al mínimo de los efectivos burocráticos puesto en marcha el año pasado en los comités provinciales del PC, se han eliminado también los puestos de suplentes del buró político (13) y del comité central (79), así como ciertos organismos ineficaces.

El buró político pasa de 26 a 25 miembros, aunque 
ahora son todos titulares. Desaparecen varios miembros históricos, como Vilma Espín, esposa de Raúl Castro y presidenta de la Asociación de Mujeres Cubanas; Armando Hart, ministro de Cultura; Julián Camacho, ex embajador en la URSS, Pedro Miret, Jose Ramón Fernández y Jorge Risquets. Entre los nuevos miembros destacan Roberto Robaina, Secretario de la UJC y Abel Prieto.

El nuevo comité central pasa de 149 miembros a 225 titulares. Se renovará en un 50\%, con 126 nuevas incorporaciones, principalmente procedentes de las jóvenes generaciones, "para hacer frente a la nueva situación". La edad media pasa de 52 a 47 años. Si se consideran las cifras globales, los afectados de la desburocratización han sido ciertamente limitados.

Este comité tendrá facultades especiales para tomar las decisiones políticas y económicas necesarias para hacer frente a la crisis en la que se encuentra sumido el país, del mismo modo que si se tratara de un comité de emergencia nacional.

En cuanto a las reformas internas para aumentar la representatividad del Partido sobre los diez millones de cubanos que habitan en la isla, se ha decidido permitir la afiliación de los creyentes. En realidad se trata de una mera formalidad ya que el partido cuenta con cristianos en sus filas desde hace tiempo. El Estado pasa así de ateo a laico.

Más prometedora es la propuesta realizada por Carlos Aldana (junto con Robaina, el más proclive a hacer reformas en el Partido) sobre la elección directa de los miembros de la Asamblea Nacional y de las asambleas provinciales. El Congreso no la aprobó por unanimidad y deberá presentarse aún ante la Asamblea Nacional. Esta reforma implicaría cambios en la Constitución (que de cualquier modo deberá ser modificada en su artículo 12, sobre las relaciones con la URSS) en lo referente a mecanismos electorales. Los candidatos serán propuestos por las asociaciones de vecinos, controladas por el partido, pero votados por elección directa. $\mathrm{El}$ alcance de esta medida no parece excesivamente renovador, dado el escaso papel que juega en la práctica la Asamblea Nacional y el rechazo radical de Castro hacia el pluripartidismo (calificado de "pluriporquería"), pero deja abierta la esperanza para que en algún momento puedan presentarse candidatos independientes. Recientemente Castro ha admitido la posibilidad de que los partidarios de la revolución pierdan la mayoría en el parlamento con el nuevo sistema de elecciones directas. Hay algunos intentos de reforzar el discreto papel de la Asamblea Nacional, aumentando el número de las comisiones de trabajo y ampliando sus facultades y sus responsabilidades.

También serán revisadas algunas de las regulaciones que rigen la organización y el funcionamiento de los órganos provinciales y municipales del Poder Popular, separando los órganos estatales de caracter representativo de los órganos ejecutivo-administrativos, de modo que los delegados aumenten su capacidad de control y su autoridad sobre los entes administrativos.

Todas estas medidas, destinadas a reducir la burocratiza- ción, agilizar los mecanismos internos del partido e incrementar la eficacia y la democracia internas no han parecido suficientes. La oposición democrática en el interior, agrupada en el Concertación Democrática Cubana, celebró una rueda de prensa tres días antes del Congreso en la que solicitó amnistía general para todos los presos políticos, la convocatoria de elecciones libres y la creación de un consejo provisional de gobierno. Ninguna de sus peticiones han sido consideradas y varios miembros de la plataforma de disidentes fueron detenidos, aunque no los principales dirigentes.

En el plano ideológico no se retrocede ni un paso: se reafirman los principios del régimen siguiendo la linea martiana y marxista, y Cuba queda como la reserva espiritual del socialismo. Se reitera la necesidad de combatir la "ideología burguesa y el individualismo pequeñoburgués, el escepticismo, las tendencias liberaloides, el derrotismo, la falta de fé y las conductas antisociales" (en alusión al preocupante aumento de la delincuencia, el mercado negro y la corrupción). El nuevo borrador del programa insiste en la influencia que el partido debe tener en la sociedad y define el sistema nacional como una estrategia de movilización de masas, "guerra de todo el pueblo" contra un posible ataque del imperialismo. Análisis diplomáticos consideran que el Partido Comunista ya no pretende ser la vanguardia del proletariado, sino un movimiento de salvación nacional en el que la ideología comunista imperante, a pesar de la "inclaudicable adhesión al ideal comunista", está cediendo, en parte, a favor del patriotismo.

\section{ASPECTOS ECONOMICOS.}

El segundo día del Congreso Fidel Castro presentó ante los 1.761 delegados un dramático informe sobre la situación económica del país, de la que en buena parte se culpa a la URSS. Cuba está a nivel cero de provisiones y no se sabe si el próximo año se recibirá petróleo procedente de la Unión Soviética, de la que se depende en un 95\%. El precio del azúcar pagado por el antiguo socio ha bajado de $800 \$$ la tonelada a tan solo 300 , lo que ha obligado a eliminar la importación de todo tipo de maquinaria, bienes de equipo y ciertos elementos secundarios, así como a reducir las de combustible, alimentos y algunas materias primas. La URSS sólo ha cumplido sus compromisos en el suministro de crudos (10 millones de toneladas para 1991) y el sistema productivo de Cuba está prácticamente paralizado. Esta situación de crisis en tiempo de paz se ha denominado Periodo Especial, y para lograr salir de él se apela a la capacidad de sacrificio y voluntad de cooperación del pueblo cubano.

Robaina reconoció el error político que supuso la aplicación en Cuba de modelos económicos socialistas hoy desaparecidos. El Proceso de Rectificación ya no se ajusta a la realidad y es necesario buscar un nuevo modelo, cuyo objetivo de momento consiste en "hacerle la vida imposible al enemigo e impedir a toda costa establecer su orden imperialista". Sin embargo las propuestas has sido verdaderamente mínimas. 
La más relevante ha sido la aceptación del trabajo "personal por cuenta propia” que efectará a mecánicos, fontaneros, carpinteros, peluqueros y demás profesionales que trabajan en pequeños servicios, así como a pequeños comerciantes. El objetivo es hacer frente al mal funcionamiento de estos servicios y sacar a la luz trabajo que antes era negro. Aún está por ver si la medida será extendida a otras actividades o si se desarrollará restrictivamente.

Una de las reformas más esperadas y que contaba con el apoyo de los delegados era la vuelta a la venta directa de los excedentes agrícolas, cortada en seco por el Proceso de Rectificación. Castro dió a conocer su voluntad contraria y fue respaldado, argumentando que los mecanismos de mercado producen corrupción y frenan el movimiento cooperativo.

A pesar del rechazo al modelo capitalista, Castro reconoció la necesidad de convivir con él, por lo que se desarrollará la política de inversiones mixtas que se viene llevando a cabo desde hace varios años, con especial atención a los paises de América Latina. El ámbito de aplicación es fundamentalmente el turismo, que produce unos ingresos apreciables pero de eficacia limitada (400 millones de dólares en 1991). Castro pide comprensión y sacrificio, y afirma que esto no contradice en ningún sentido los ideales revolucionarios, que deben mantenerse siempre vigentes en el espíritu del pueblo.

\section{CONCLUSIONES.}

El IV Congreso del Partido Comunista de Cuba puede resumirse en dos ideas: intransigencia ideológica e incapacidad para presentar soluciones a la situación insostenible en que se encuentra la isla. Esta postura ha defraudado a muchos que, conscientes de que la situación no puede sos- tenerse así por mucho tiempo, desean una transición no violenta para el país.

Es el caso de países como Venezuela, Colombia y México, que están dispuestos a ayudar a Castro a cambio de una apertura del régimen sin plazo prefijado. También es el de España y el de la antigua URSS, que se ofreció a mediar entre Washington y La Habana para flexibilizar el bloqueo económico que Estados Unidos mantiene desde hace treinta años y que en gran parte ha favorecido la radicalización del régimen cubano. Sin embargo en el Congreso no se ha ofrecido un panorama de disposición al cambio, dando así argumentos a Estados Unidos para que continúe con su actitud hostil.

Es necesario esperar para ver cómo se interpretan las modificaciones proyectadas, porque no se podrán cerrar los ojos por mucho más tiempo. El futuro del país está, para casi todos los observadores, en el pluralismo político y en la liberalización económica. El problema es cómo y cuándo.

Castro no ha tenido más remedio que llamar al capital extranjero a invertir en la isla y permitir la iniciativa privada en ciertos servicios. Esto no dejará de repercutir en las percepciones de la sociedad cubana. Por otro lado, los efectos del nuevo sistema electoral dependerán del tipo de regulación que se establezca y el propio Castro ha reconocido que podría introducir cambios significativos, como que los partidarios de la revolución quedaran en minoría en la Asamblea.

En cualquier caso no hay que olvidar que el status quo se puede mantener a corto plazo. No nos encontramos ante un país del Este con fronteras porosas y un funcionamiento gris en el papel de líder. Castro es, en este caso, un elemento fundamental; el otro es cuánto tiempo los cubanos podrán aguantar una dieta de "sol y sacrificio".

\section{RESUMEN}

El IV Congreso del Partido Comunista de Cuba, celebrado en octubre de 1991, estuvo marcado por una voluntad continuista. Aunque el país atraviesa una de sus peores crisis, las reformas fueron pocas, dirigidas principalmente a aumentar la representatividad del partido y el grado de democracia en su funcionamiento interno. En el aspecto económico el único cambio fue el permitir a ciertas categorías profesionales el trabajo por cuenta propia.

\section{ABSTRACT}

The IV congress of the Cuban Communist Party, held in October 1991 showed a will of continuity. Although the country must cope with the worst crisis ever suffered reforms are not as many as expected. The congress aproved some modest changes intended to make the party more democratic in its inner working and more representative, such as the direct election of the National Assembly members. The sole concession made to free markets was to allow small tradesmen to work on their own account.

NOTAS:

(1) El Mundo, 13 de octubre de 1991. • (2) El País, 25 de octubre de 1991

(3) Resolución sobre el perfeccionamiento de la organización y funcionamiento de los órganos del poder popular. IV Congreso del PC de Cuba, en América Latina Hoy, $\mathrm{n}^{\circ} 2$, noviembre, 1991.

(4) El País, 13 de octubre de 1991. - (5) El País, 12 de octubre de 1991. (6) El País, 14 de octubre de 1991.

(7) RITTER, A.R.M. hace un interesante análisis de los posibles escenarios futuros en "Prospects for Economic and Political Change in Cuba in the 1990s", en RITTER et al. (eds.) Latin America to the year 2000: Reactivating Growth, Improving Equity, Sustaining Development. Praeger, New York, 1991

(8) The Economist, 19 al 25 de octubre de 1991. 